\title{
Size and Charge Adaptive Clustered Nanoparticles Targeting Biofilm Microenvironment for Chronic Lung Infection Management
}

Yifan Gao, Jing Wang, Mengying Chai, Xu Li, Yongyan Deng, Qiao Jin*, Jian Ji*

MOE Key Laboratory of Macromolecule Synthesis and Functionalization of Ministry of

Education, Department of Polymer Science and Engineering, Zhejiang University,

Hangzhou, 310027, China

E-mail: jinqiao@zju.edu.cn (Q. Jin)

jijian@zju.edu.cn (J. Ji) 


\section{Experimental Section}

\section{Materials}

Poly(amidoamine) dendrimer (PAMAM, ethylenediamine core, G4.0, Sigma-Aldrich), methoxy polyethylene glycol amine (PEG-NH,$~ M W ~ 5 K)$, azithromycin (AZM, Dalian Meilun Biotechnology Co., LDT.), Rhodamine B isothiocyanate, 4', 6-diamidino-2phenylindole (DAPI, Invitrogen), seaweed alginate (Sigma-Aldrich), 3-(4,5-dimethyl-thiazol-2yl)-2,5-diphenyl tetrazolium bromide (MTT, Sigma-Aldrich), N-phenylnaphthylamine (NPN, TCI), BacLight Bacterial Membrane Potential Kit (Invitrogen) were used as received. MilliQwater (18.2 $\mathrm{MX} \mathrm{cm}^{-1}$ ) was obtained using a Millipore Milli-Q Academic Water Purification System. Gram (-) Pseudomonas aeruginosa (PAO1) was purchased from Guangdong culture collection center for all bacteria experiments. Human umbilical vein endothelial cells (ECs) were purchased from Lonza (C2519A, USA) for cell experiments. All other reagents were used as received without further purification.

\section{Characterizations}

${ }^{1} \mathrm{H}$ NMR spectra were recorded on a Bruker DMX500 spectrometer. The mass spectra were recorded on a Bruker Esquire 3000 plus ion trap mass spectrometer equipped with an ESI source. Matrix assisted laser desorption/ionization time-of-flight mass spectrometry (MALDI-TOF-MS) was performed on a Bruker's ultrafleXtreme ${ }^{\mathrm{TM}}$ MALDI-TOF mass spectrometer. Samples were spotted using dried-droplet method. 2, 5-dihydroxybenzoic acid (DHBA) was used as matrix. Molecular weight and molecular weight distribution of the 
polymers were obtained by gel permeation chromatography multi-angle laser light scattering (GPC/MALLS, Wyatt Technology Crop., WH2-05, USA). DMF containing $0.05 \mathrm{~mol} \mathrm{~L}^{-1} \mathrm{LiBr}$ was used as the eluent with a flow rate of $1.0 \mathrm{~mL} \mathrm{~min}^{-1}$ at $60^{\circ} \mathrm{C}$. The hydrodynamic diameter (Dh) and zeta potential of the nanoparticles were measured by dynamic light scattering (DLS) measurements using Zetasizer Nano-ZS from Malvern Instruments equipped with a He-Ne laser $(633 \mathrm{~nm})$ at room temperature. The samples were filtered using a $0.45 \mu \mathrm{m}$ Millipore filter before measurements. The sizes and morphologies of the nanoparticles were characterized by JEM-1200 transmission electron microscopy (TEM) at an accelerating voltage of $80 \mathrm{kV} .20 \mu \mathrm{L}$ of the nanoparticle solution was added onto a carbon-coated copper grid using a pipette and then dried under infrared light. Staining agents were not used in TEM measurements. UV-vis spectra were recorded using a Shimadzu UV-2550 UV-vis spectrometer. The fluorometric measurements were carried out using a ShimadzuRF-530 spectrometer. Fluorescence images were observed using a confocal laser scanning microscope (Leica TCS SP5) and flow cytometry analysis was analyzed by a BD FACS-CaliburTM flow cytometer. In vivo body fluorescent imaging was obtained with a CRI Maestro in vivo imaging system which equipping with a tunable liquid-crystal filter and a cooled scientificgrade monochrome CCD camera.

\section{Synthesis of Succinic Acid Modified AZM (AZM-COOH)}

AZM-COOH was synthesized by the reaction of AZM and succinic anhydride. Briefly, $1 \mathrm{~g}$ (1.274 mmol) of AZM was added dissolved in $20 \mathrm{~mL}$ of $\mathrm{N}, \mathrm{N}$-dimethylformamide (DMF). 127.4 $\mathrm{mg}(1.274 \mathrm{mmol})$ of succinic anhydride and $300 \mu \mathrm{L}$ of triethylamine (TEA) were added. The 
reaction mixture was stirred for $24 \mathrm{~h}$. DMF was then removed under reduced pressure. The resulting crude product was purified by column chromatography using methanol: ethyl acetate: petroleum ether $(1: 2: 1)$ as eluent. Yield: $47.6 \%$.

\section{Synthesis of AZM Conjugated PAMAM (PAMAM-AZM)}

To a stirred solution of AZM-COOH (90 mg, $0.1 \mathrm{mmol})$ in $10 \mathrm{~mL}$ of DMSO, DCC (22 mg, 0.1 mmol), DMAP (13 mg, $0.1 \mathrm{mmol})$, and TEA $(500 \mu \mathrm{L})$ were added to the reaction mixture. After 1 hour of stirring, amino-terminated PAMAM dendrimer (G4-NH2 $143 \mathrm{mg}, 1 \mathrm{mmol})$ was added. The mixture was stirred for $48 \mathrm{~h}$. The reaction mixture was purified by dialysis using dialysis membrane (MWCO 1,000 Da) with DMF for $48 \mathrm{~h}$ and Milli-Q water for another $48 \mathrm{~h}$. The product was then freeze-dried and stored at $4{ }^{\circ} \mathrm{C}$. Yield: $58.2 \%$.

\section{Synthesized of Rho B labeled PAMAM-AZM}

To synthesized Rho B labeled PAMAM-AZM, 50 mg of PAMAM-AZM was dissolved in 4 $\mathrm{mL}$ of ethanol. $7.5 \mathrm{mg}$ of Rhodamine $\mathrm{B}$ isothiocyanate in $1 \mathrm{~mL}$ ethanol was added. After adding $30 \mu \mathrm{L}$ TEA, the solution was stirred at room temperature for $24 \mathrm{~h}$ in dark. The solution was then dialyzed against Milli-Q water for $96 \mathrm{~h}$ to remove unreacted Rho B. The final product was then freeze-dried and stored at $-18^{\circ} \mathrm{C}$.

\section{Synthesis of N- $\varepsilon$-Carbobenzoxy-L-lysine-N-carboxyanhydride (Lys(Z)-NCA)}

Under an argon atmosphere, $\varepsilon$-Lys(Z) $(5.0 \mathrm{~g}, 18 \mathrm{mmol})$ was dissolved in $40 \mathrm{~mL}$ of dry tetrahydrofuran (THF) and stirred at $50{ }^{\circ} \mathrm{C}$ for $10 \mathrm{~min}$ in a three-necked flask $(100 \mathrm{~mL})$. Triphosgene $(2.7 \mathrm{~g}, 9 \mathrm{mmol})$ and dry THF $(10 \mathrm{~mL})$ solution was then slowly added through a dropping funnel. The reaction solution turned into a gel immediately and the magnetic 
stirrer was restricted. After $1 \mathrm{~h}$, it changed to a transparent yellow liquid. The whole process was maintained for $2 \mathrm{~h}$. Then, the mixture was concentrated by using a rotary evaporator at $30{ }^{\circ} \mathrm{C}$ and purified by precipitating three times from THF into an excess amount of hexane. After vacuum drying, a white powder of Lys(Z)-NCA was obtained and stored at $-18 \stackrel{\circ}{\circ}$. Yield: $78.6 \%$

\section{Synthesis of poly(ethylene glycol)-block-poly(L-lysine) (PEG-b-PLys)}

PEG-b-PLys was synthesized through ring-opening polymerization (ROP) of activated NCA monomers with amino-terminated PEG as macroinitiators and subsequent deprotection of carbobenzoxy groups. Firstly, all the reaction vessels were completely dried by using an alcohol blast burner and continuously filled with argon. $\mathrm{PEG}-\mathrm{NH}_{2}(0.5 \mathrm{~g}, 0.1 \mathrm{mmol})$ and Lys(Z)-NCA (2.1 g, $7 \mathrm{mmol}$ ) were dissolved in $5 \mathrm{~mL}$ of dry DMF. The reaction was maintained for 3 days at $35{ }^{\circ} \mathrm{C}$ under oxygen free conditions. After polymerization, the crude product PEG-b-PLys(Z) was precipitated into an excess amount of diethyl ether. The polymerization degree of Lys(Z)-NCA was 66 calculated from the ${ }^{1} \mathrm{H}$ NMR results in Figure S5.

To deprotect carbobenzoxy groups, PEG-b-PLys(Z) (1.3 g) was dissolved in cold trifluoroacetic acid $(13 \mathrm{~mL})$ in a round-bottom flask $(25 \mathrm{~mL})$. Then $3.9 \mathrm{~mL} \mathrm{HBr} /$ acetic acid (HOAc) (33 wt \%) was added dropwise. The mixture was stirred at room temperature for $1 \mathrm{~h}$. The crude product was obtained by precipitating into excess diethyl ether. After filtration, the filter cake was dissolved in distilled water and dialyzed (MWCO 3,500 Da) against distilled water for $48 \mathrm{~h}$. A white powder of PEG-b-PLys was obtained by freeze drying. 


\section{Synthesis of DA modified PEG-b-PLys and SA modified PEG-b-PLys}

In order to synthesize DA modified PEG-b-PLys, 100 mg of PEG-b-PLys was added into 10 $\mathrm{mL}$ of HEPES buffer solution ( $\mathrm{pH}$ 8.5). $60 \mathrm{mg}$ of DA was then added in three times (20 mg X3). The solution $\mathrm{pH}$ was kept at 8.5 by adding $\mathrm{NaOH}$ solution. After $24 \mathrm{~h}$, the solution was dialyzed in $\mathrm{pH}$ 8-9 buffer (adjust by $\mathrm{NaOH}$ ) for 3 days to remove excess DA. The resulting product was lyophilized and stored at $-20^{\circ} \mathrm{C}$. Based on the ${ }^{1} \mathrm{H}$ NMR results in Figure S7, 87.9\% of amino groups in PEG-b-PLys were converted to carboxyl groups. SA modified PEG-bPLys was synthesized using the same method. Based on the ${ }^{1} \mathrm{H}$ NMR results in Figure S7, 92.4\% of amino groups in PEG-b-PLys were converted to carboxyl groups.

\section{Virulence factors measurement}

$P$. aeruginosa were treated with subinhibitory concentrations (1/16 and 1/32 the MIC) of free AZM and nanoparticles (with equal amount of AZM). After 24 hours incubation at $\mathrm{pH}$ 6.0, bacterial suspension was centrifuged for $15 \mathrm{mins}(5,000 \mathrm{rpm})$ and the supernatant were filtered $(0.22 \mu \mathrm{m})$ for virulence factors measurement.

(1) Elastase assay. Insoluble elastin-Congo red $(10 \mathrm{mg})$ was mixed with $0.5 \mathrm{~mL}$ of filtered supernatant and agitated at $200 \mathrm{rpm}$ for 24 hours at $37^{\circ} \mathrm{C}$. Elastase secreted by bacteria will breakdown elastin-Congo red and produce a compound that can dissolve in the solution. Then, the mixtures were centrifuged and the absorbance of the supernatant were measured at OD490.

(2) Lipase assay. A $0.6 \mathrm{~mL}$ aliquot of filtered supernatant was mixed with $0.6 \mathrm{~mL}$ of $10 \%$ Tween 20 in Tris buffer, $0.1 \mathrm{~mL}$ of $1 \mathrm{M} \mathrm{CaCl}_{2}$ and $1.2 \mathrm{~mL} \mathrm{H}_{2} \mathrm{O}$ and agitated at $200 \mathrm{rpm}$ for 24 
hours at $37^{\circ} \mathrm{C}$. In the presence of lipase, Tween 20 will break down and the resulting fatty acid will bind with calcium and form an insoluble complex the absorbance of which can be measured by turbidity (OD400).

(3) Protease assay. The solid substrate was prepared with $2 \%$ agarose and $3 \%$ skimmed milk in petri dishes. Wells with $8 \mathrm{~mm}$ diameter were made in the solid substrate. Then $200 \mu \mathrm{L}$ filtered supernatant was added into the wells and incubated for 24 hours at $37^{\circ} \mathrm{C}$. The zones of clearance (diameter) around the wells were measured with calipers.

\section{Live/Dead staining of biofilms}

P. aeruginosa biofilms were cultured in glass dishes for 2 days. Then the culture medium was removed and biofilms were washed with PBS gently. Free AZM, AZM-SA NPs or AZMDA NPs were added into each well. 12 hours later, biofilms were stained with Live/Dead dye for 20 mins and washed for 3 times. LSCM was used to visualize the targeting results.

\section{MTT test}

MTT assay was employed to evaluate the cytotoxicity. Human umbilical vein endothelial cells (HUVECs) were cultured in 96-well plates at a density of 10000 cells per well. After 24 $\mathrm{h}$ incubation, the culture medium was replaced with free AZM or nanoparticles in fresh medium for further incubation of $12 \mathrm{~h}$. After that, the culture medium was replaced by fresh culture medium, $20 \mu \mathrm{L}$ MTT ( $5 \mathrm{mg} \mathrm{mL}^{-1}$ ) was added to each well and the cells were further cultured at $37^{\circ} \mathrm{C}$ for $4 \mathrm{~h}$. Finally, the media was removed and replaced with $150 \mu \mathrm{L}$ of DMSO and formazan absorbance was determined by a microplate reader at $490 \mathrm{~nm}$.

\section{Histological studies}


After treatments, the lungs were removed and fixed with $10 \%$ formalin, embedded in paraffin, sectioned and stained for pathology analysis. Hematoxylin and eosin (H\&E) staining was performed for lung structure observation. Masson's trichrome staining and Sirius Red staining were also performed for evaluating the fibrosis in the lung, which implied the physical condition of the infected lungs after treatments.

\section{Inflammation analysis}

BALF were centrifuged at $400 \mathrm{~g}$ for 10 mins to obtain the inflammatory cells. Numbers of different types of inflammatory cells were calculated under the microscopy. The supernatant was used to analyze inflammation factors (IL-1 $\beta$, IL-6, MIP-2, TNF- $\alpha$, G-CSF) by enzymelinked immunosorbent assay (ELISA) kit. 


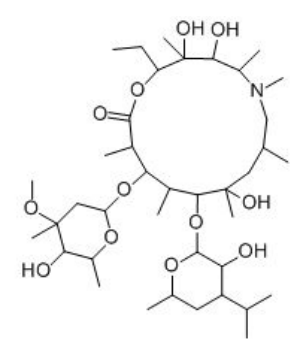

AZM

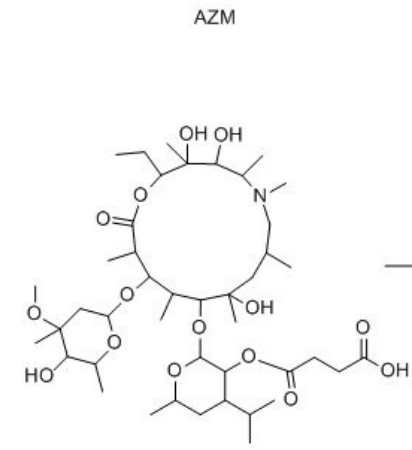

AZM-COOH

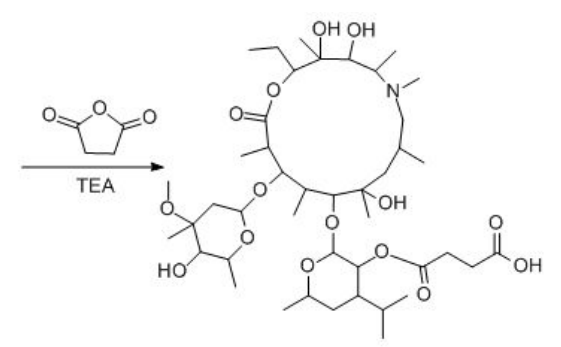

AZM-COOH

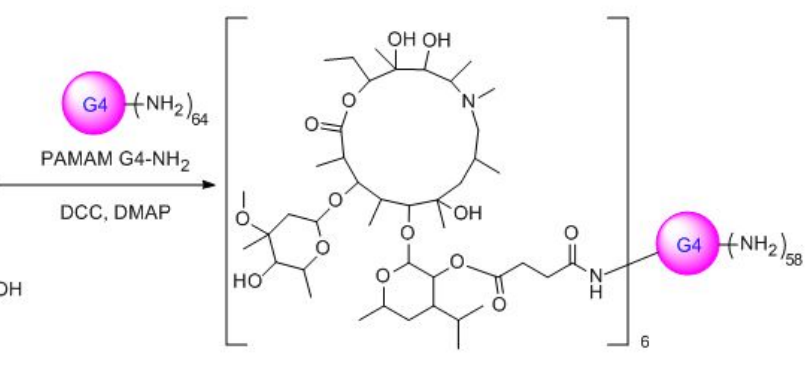

PAMAM-AZM

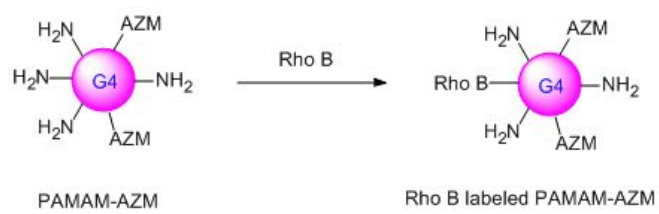

Scheme S1. Detailed synthetic routes of PAMAM-AZM and Rho B labeled PAMAM-AZM. 


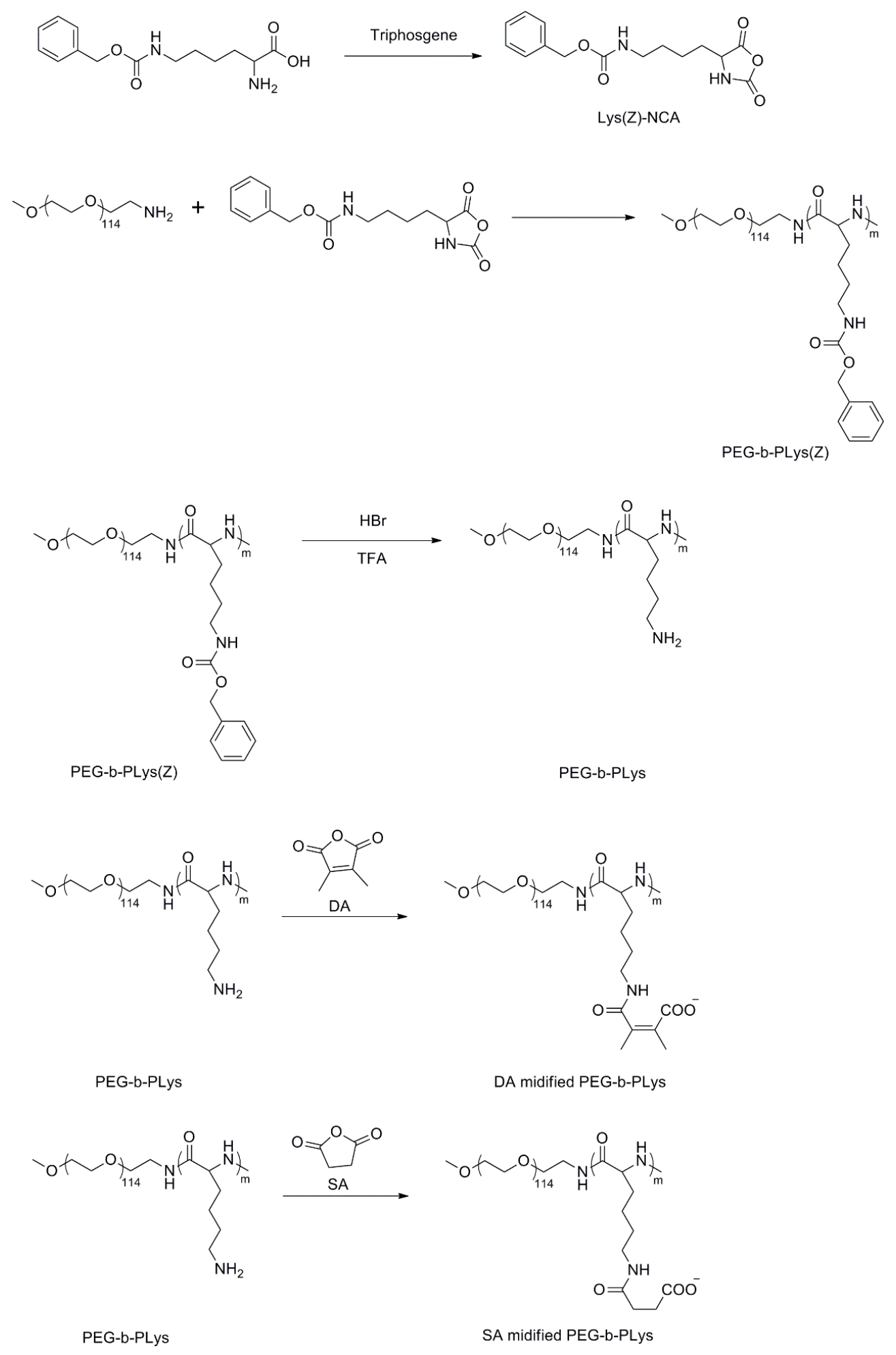

Scheme S2. Detailed synthetic routes of DA modified PEG-b-PLys and SA modified PEG-bPLys. 


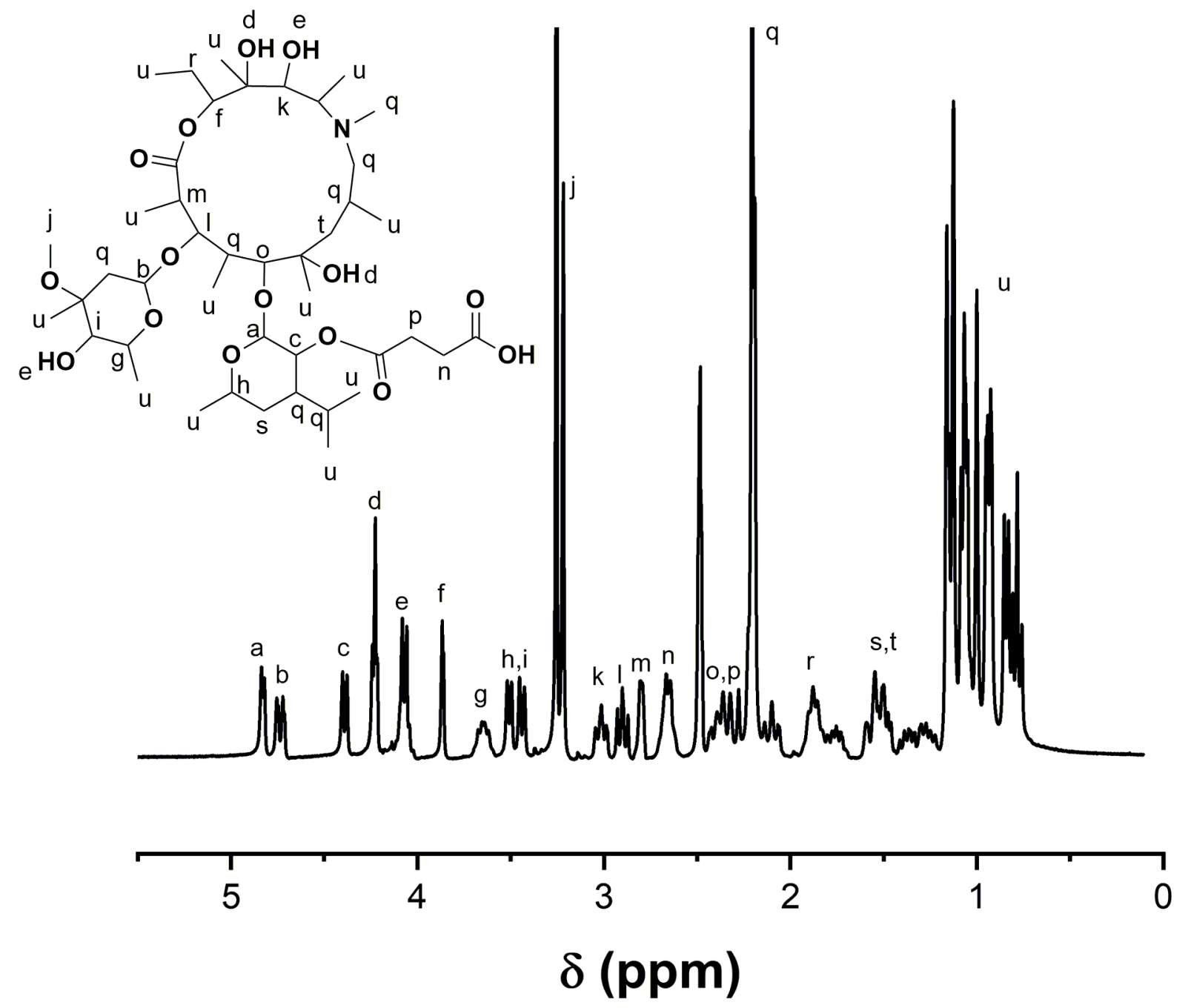

Figure $\mathrm{S} 1 .{ }^{1} \mathrm{H}$ NMR spectrum of succinic anhydride modified AZM (AZM-COOH) in DMSOd6. 


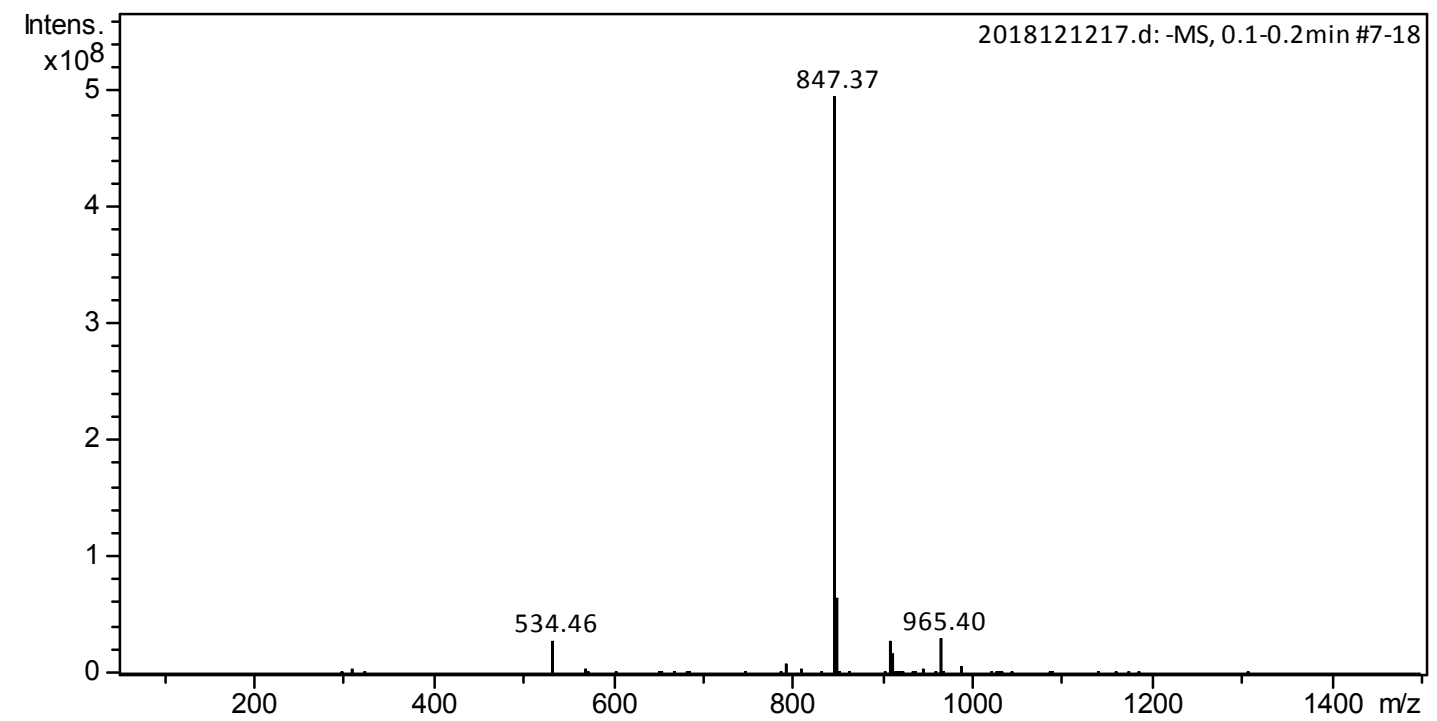

Figure S2. ESI-MS analysis of succinic anhydride modified AZM (AZM-COOH). Mw: 848.07 in theory. 


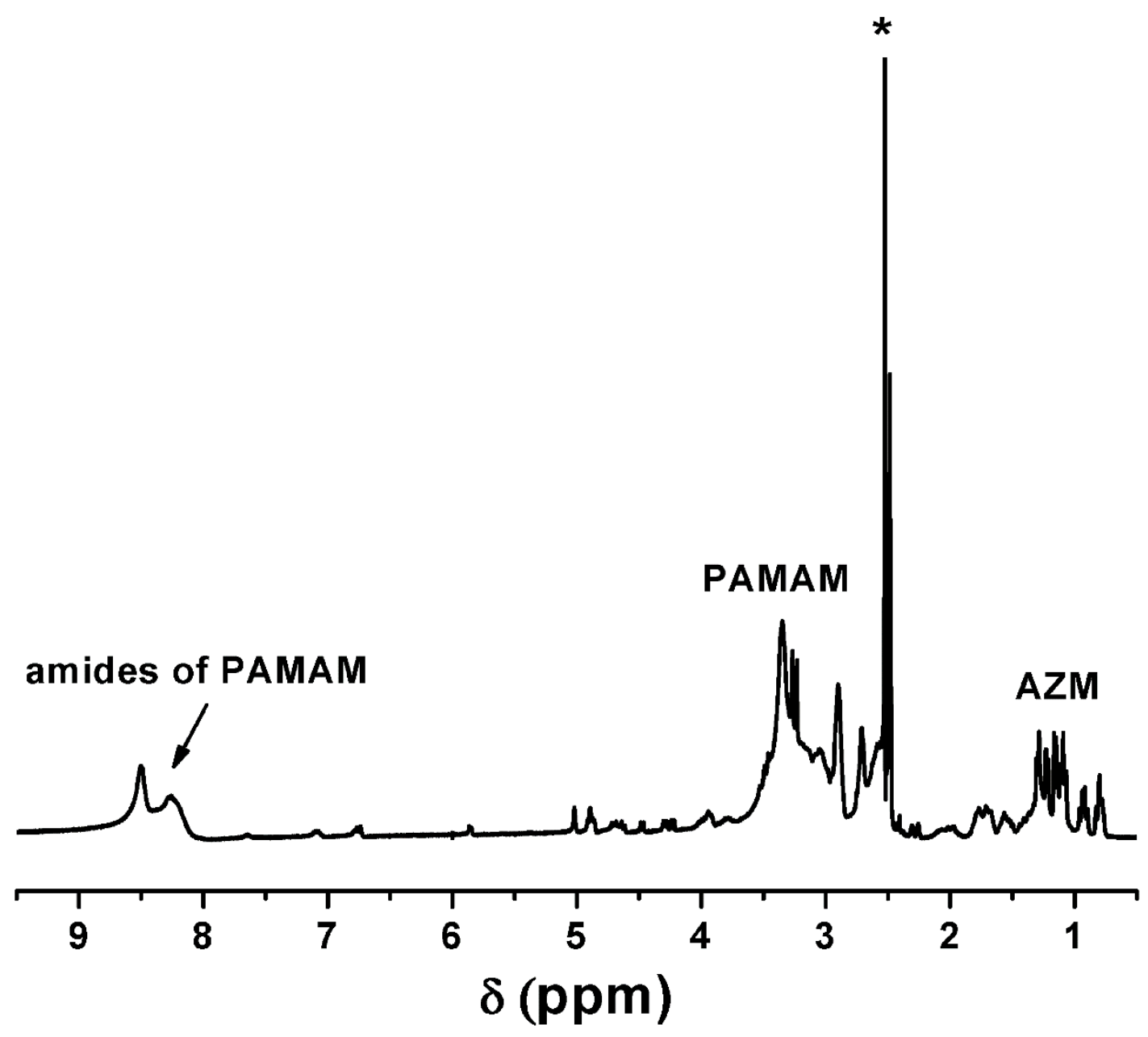

Figure S3. ${ }^{1} \mathrm{H}$ NMR spectrum of PAMAM-AZM in DMSO-d6. 


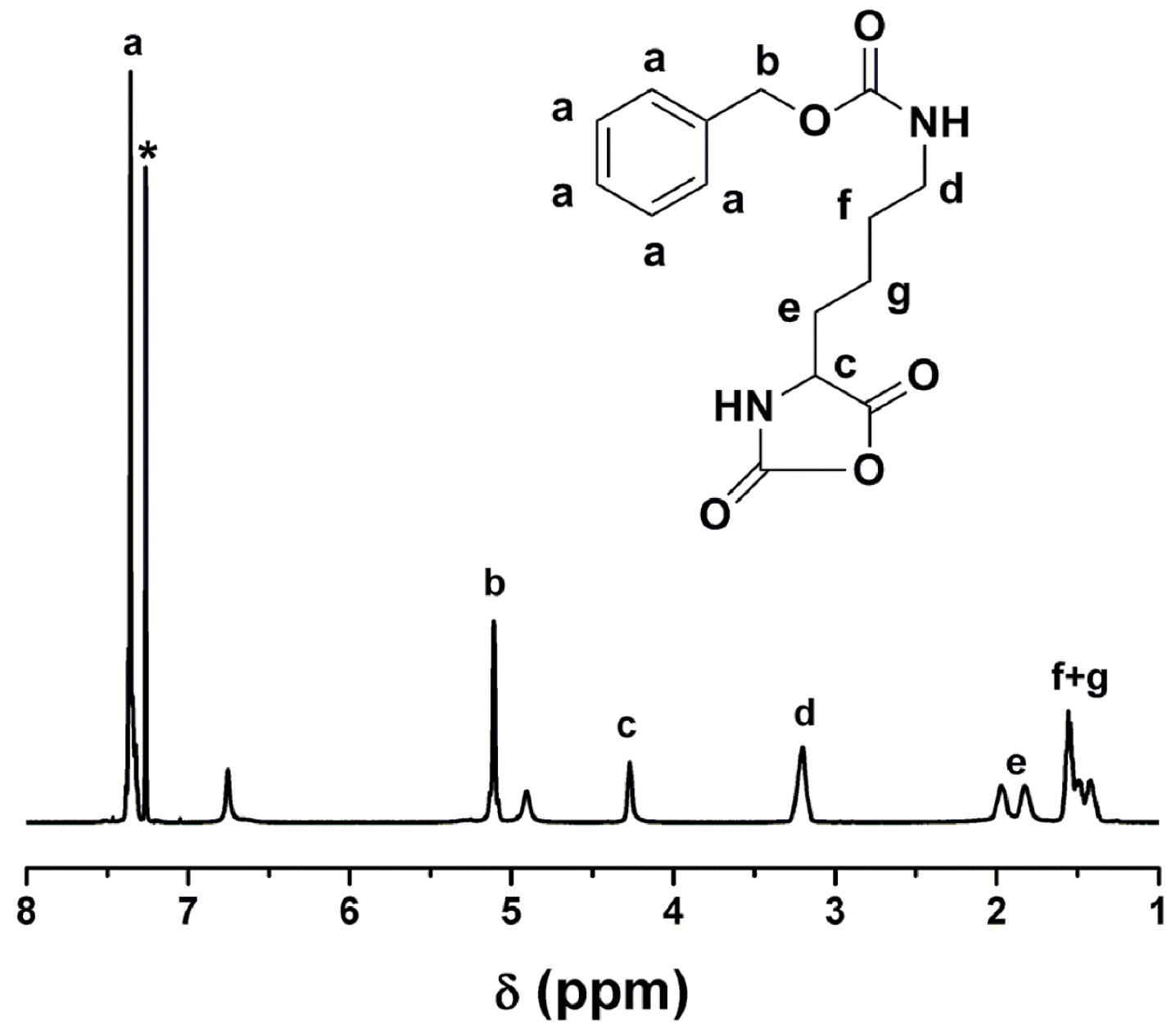

Figure S4. ${ }^{1} \mathrm{H}$ NMR spectrum of Lys(Z)-NCA in CDCl3. 
(a)

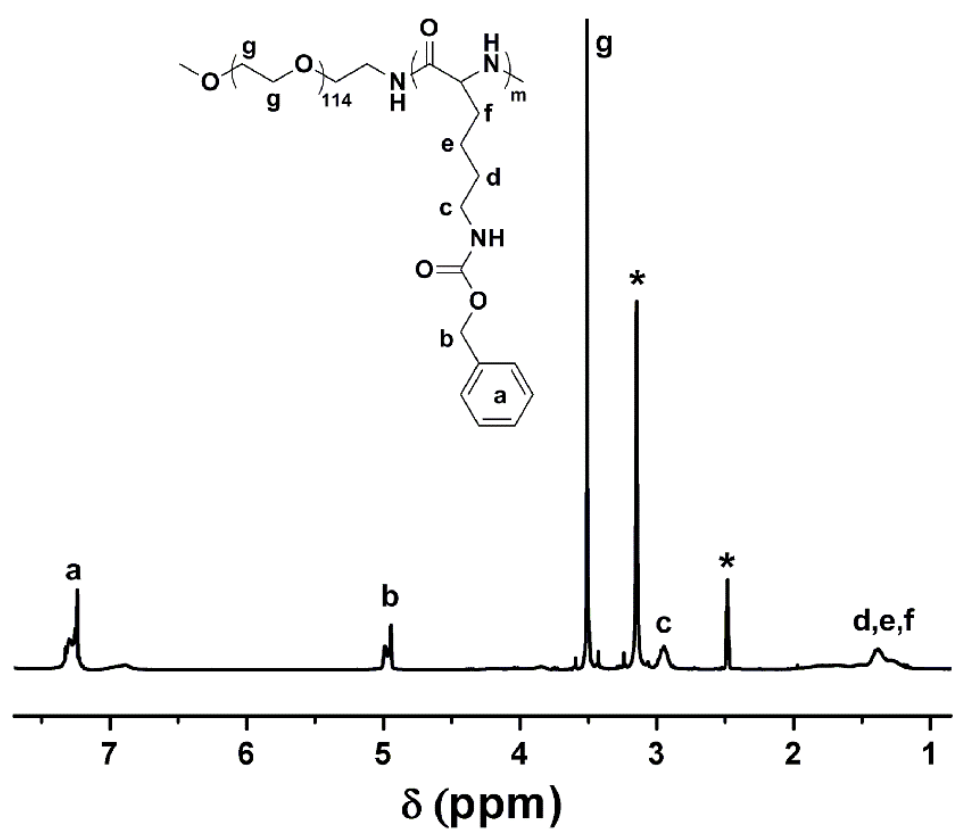

(b)

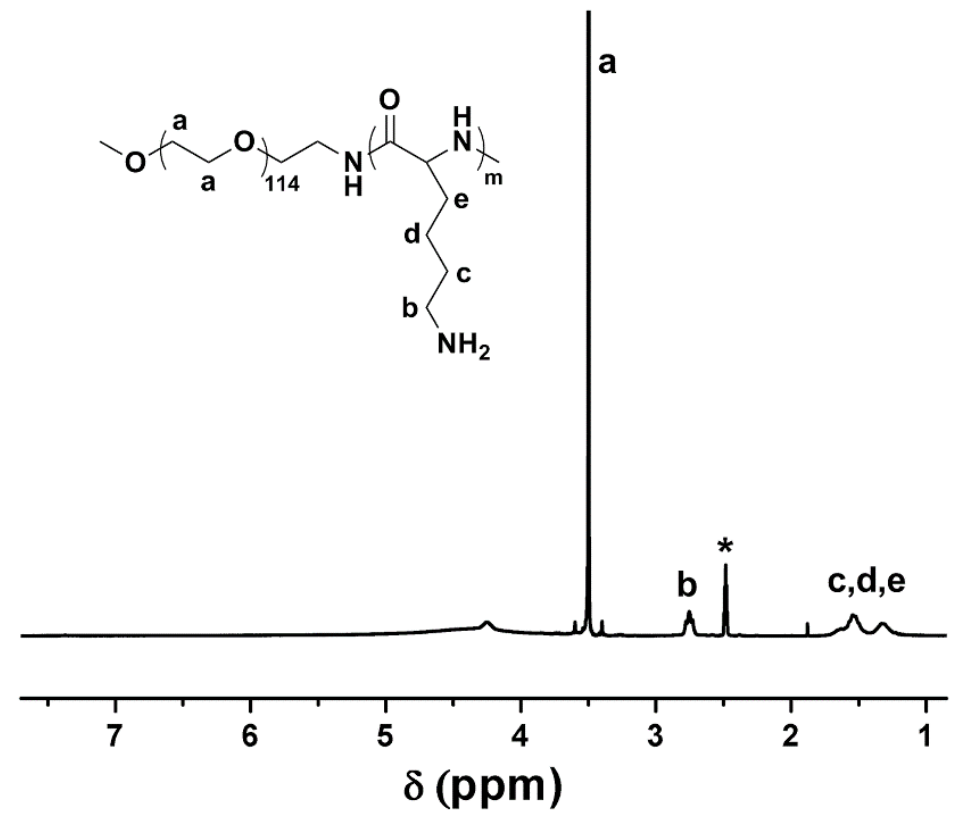

Figure S5. ${ }^{1} \mathrm{H}$ NMR spectra of (a) PEG-b-PLys(Z) and (b) PEG-b-PLys in DMSO-d6. 


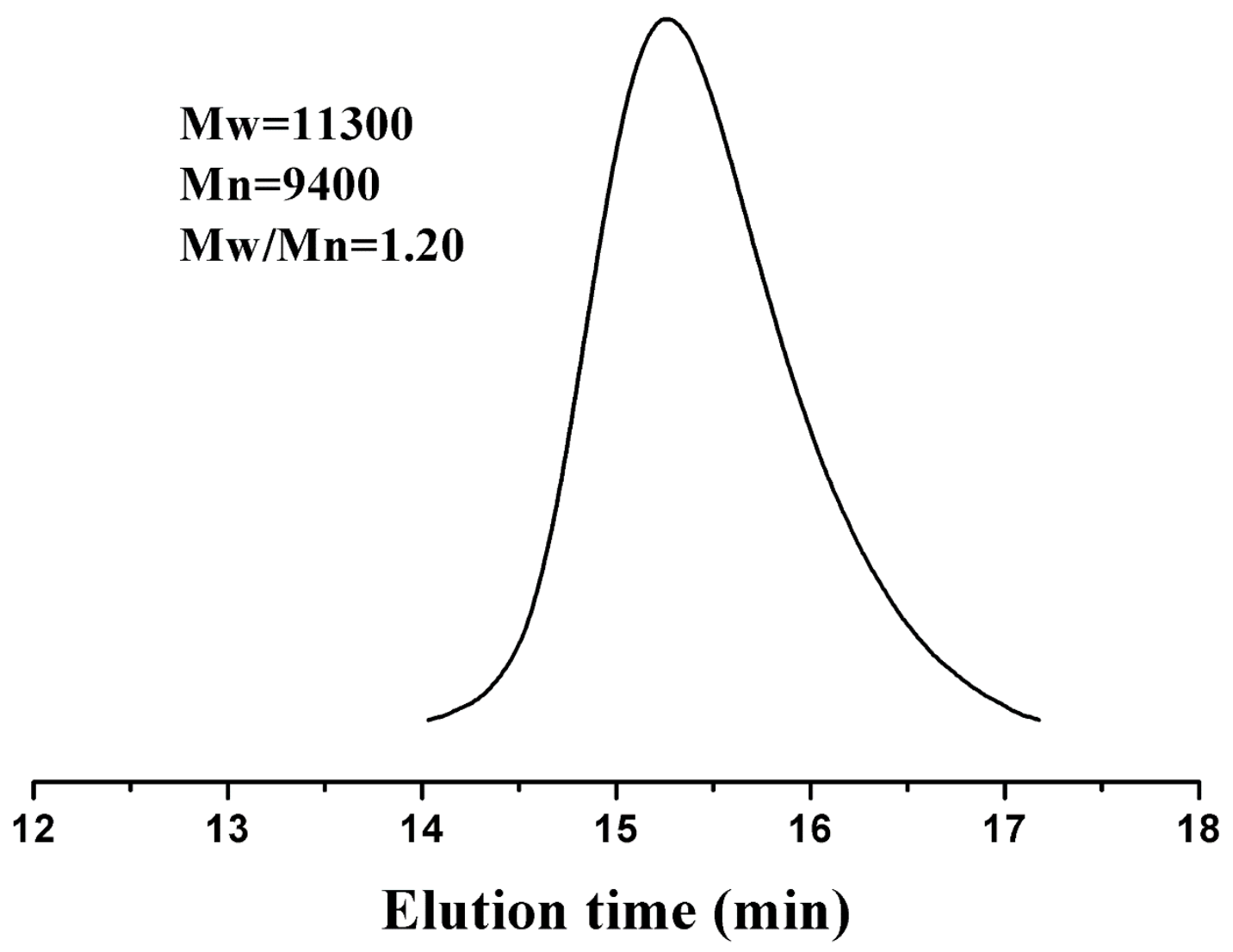

Figure S6. GPC result of PEG-b-PLys(Z). 


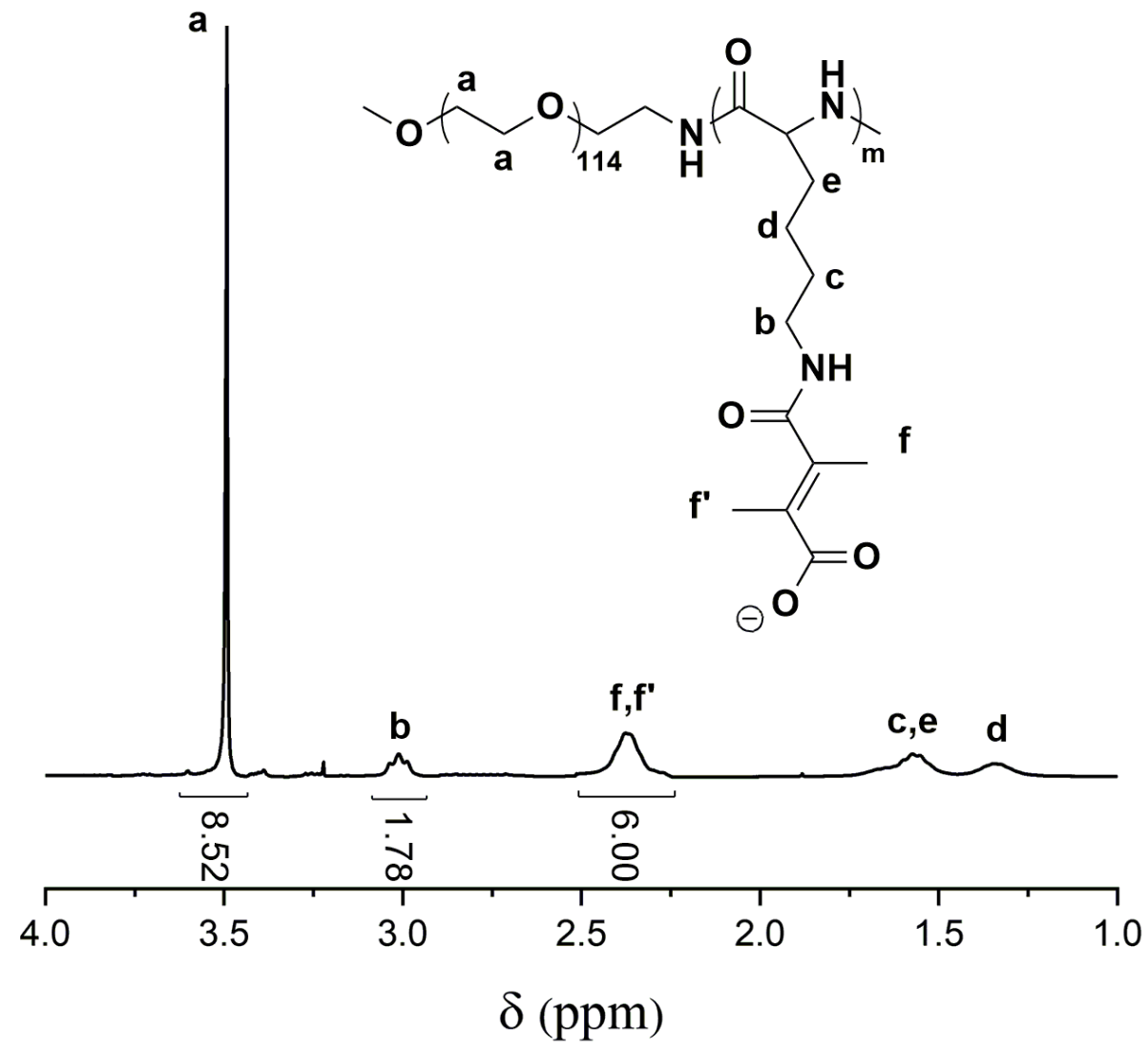

Figure S7. ${ }^{1} \mathrm{H}$ NMR spectrum of DA modified PEG-b-PLys in $\mathrm{D}_{2} \mathrm{O}$. 


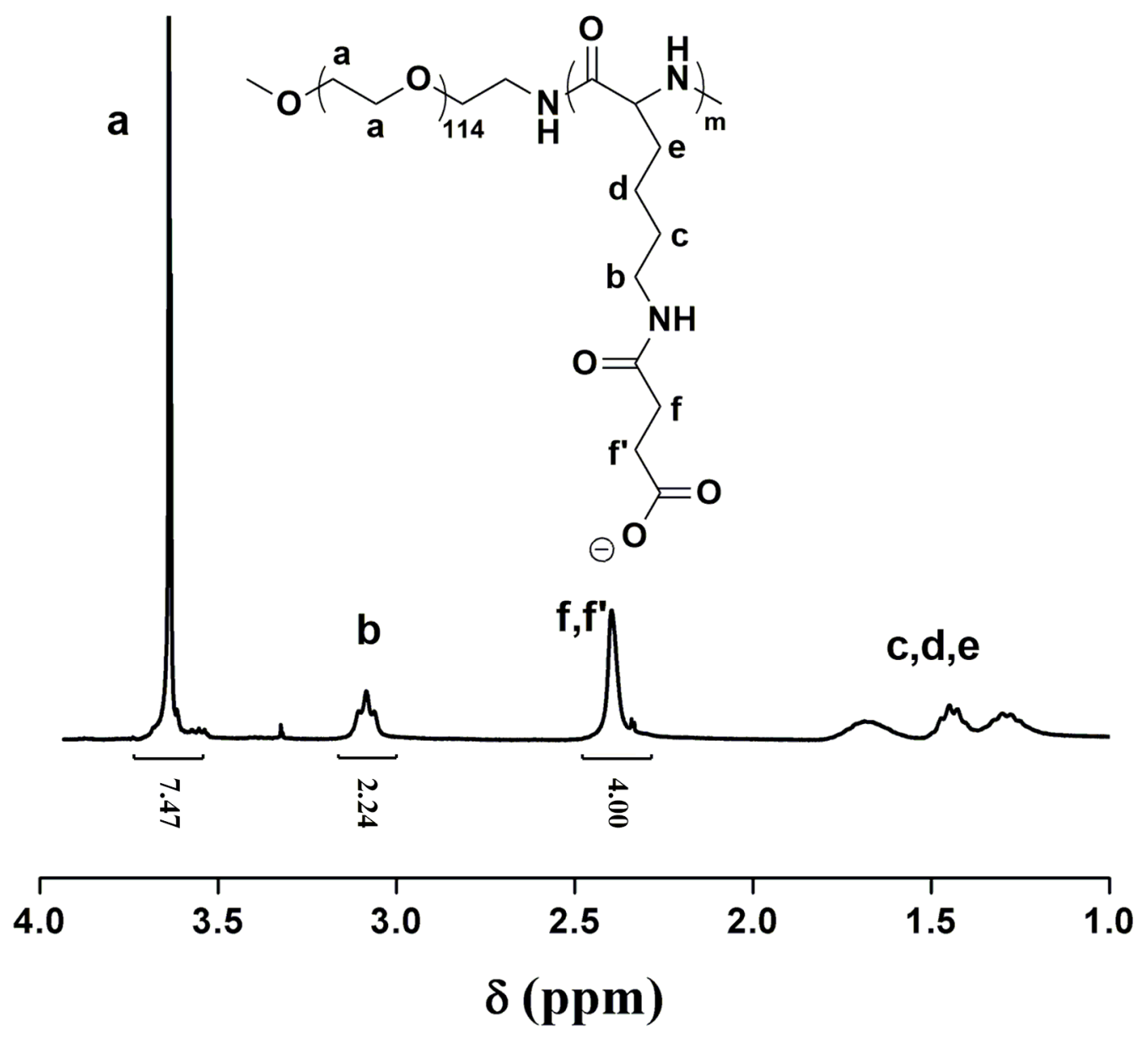

Figure S8. ${ }^{1} \mathrm{H}$ NMR spectrum of SA modified PEG-b-PLys in $\mathrm{D}_{2} \mathrm{O}$. 


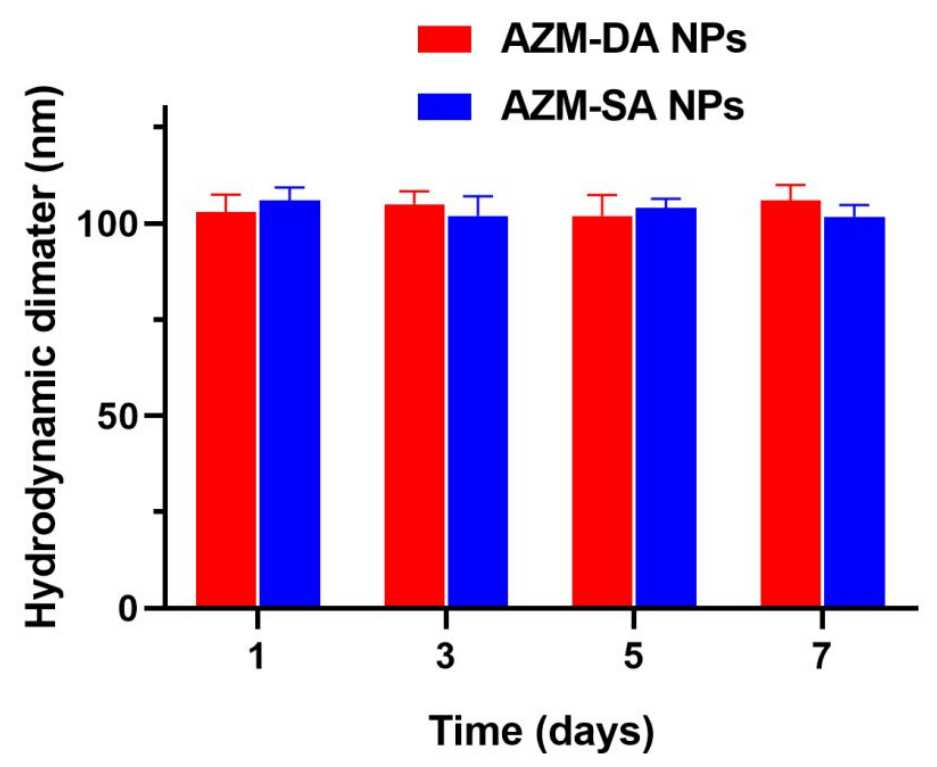

Figure S9. Hydrodynamic diameters of AZM-DA NPs and AZM-SA NPs in PBS during 7 days storage. 


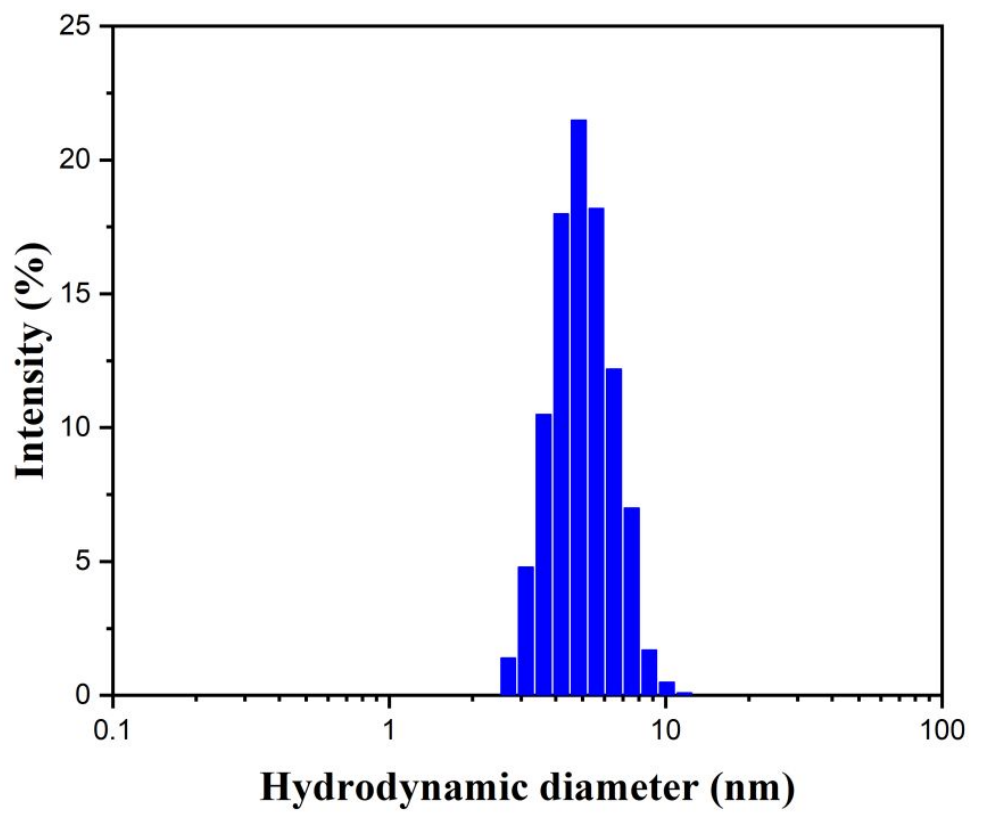

Figure S10. The hydrodynamic diameter of PAMAM-AZM at $\mathrm{pH}$ 6.0. 

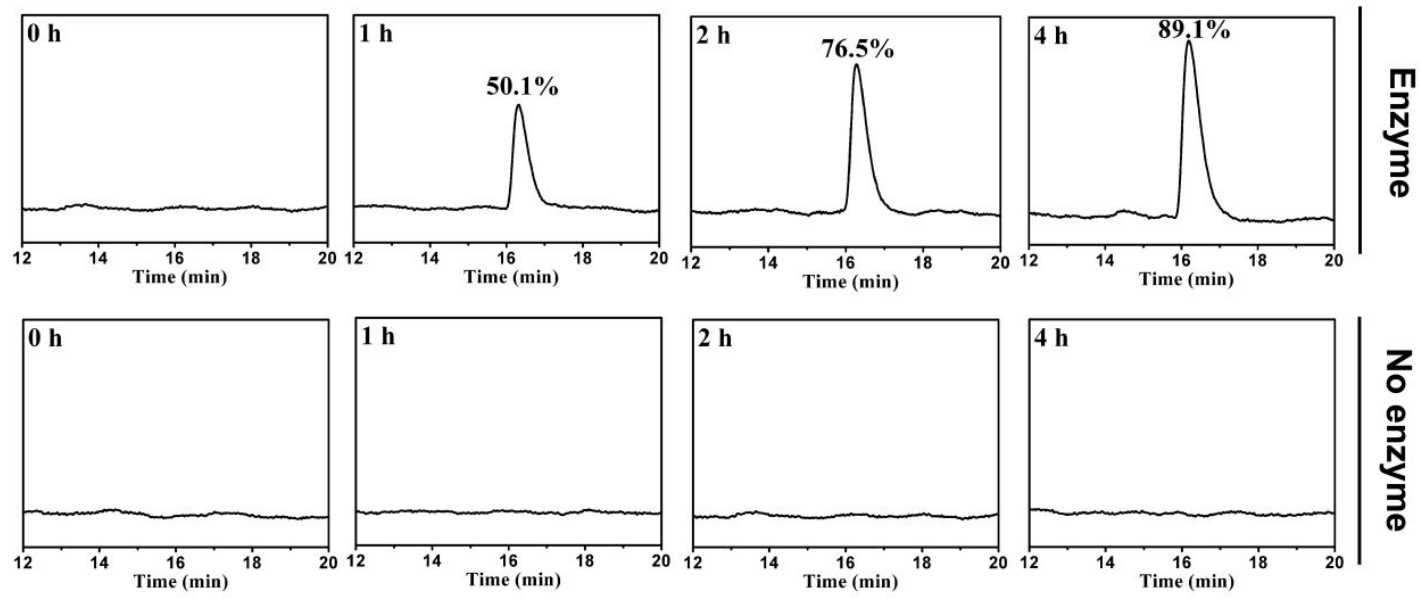

Figure S11. HPLC traces showing the release of AZM upon incubation in the presence (upper) or absence (lower) of esterase for different time intervals. 


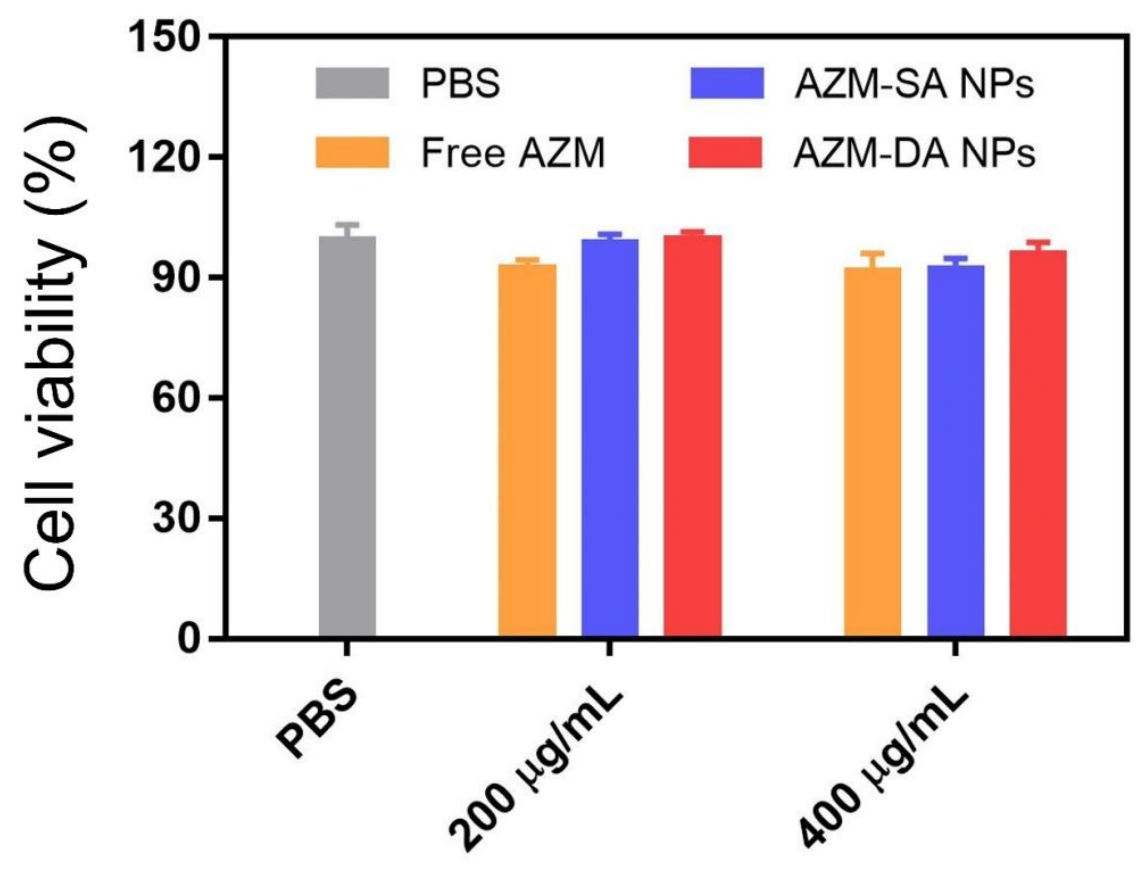

Figure S12. The in vitro cytotoxicity against HUVEC cells after incubated with free AZM, AZM-SA NPs, and AZM-DA NPs with different concentrations. 
(a)

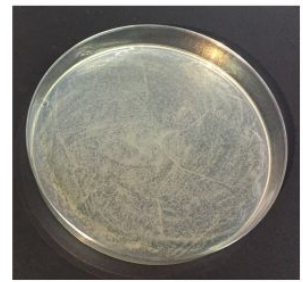

PBS

(b) $\quad$ Free AZM Blank DA NPs AZM-SA NPs AZM-DA NPs
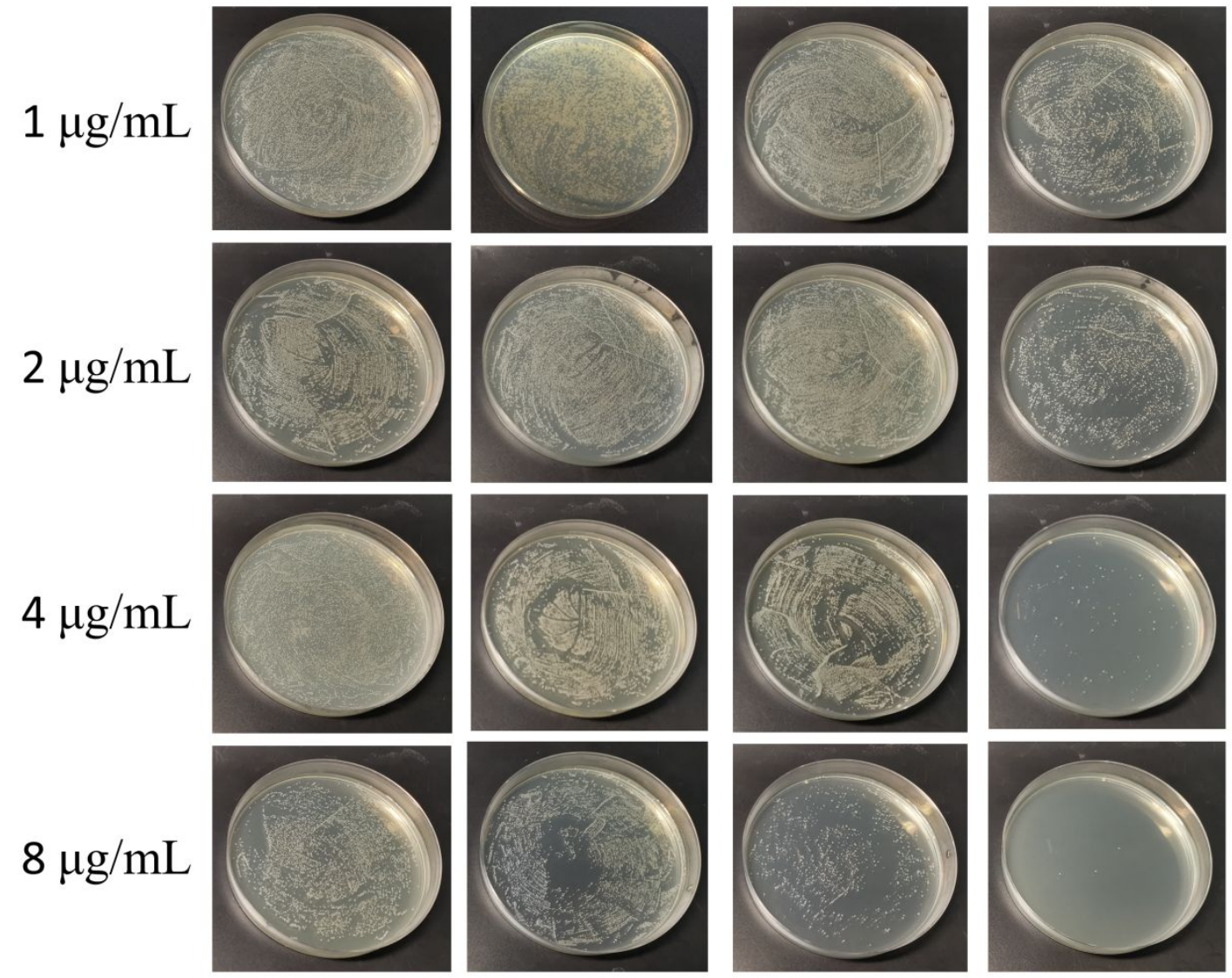

Figure S13. Antibacterial results of planktonic $P$. aeruginosa treated with (a) PBS or (b) different concentrations of free AZM, blank DA NPs, AZM-SA NPs and AZM-DA NPs. 


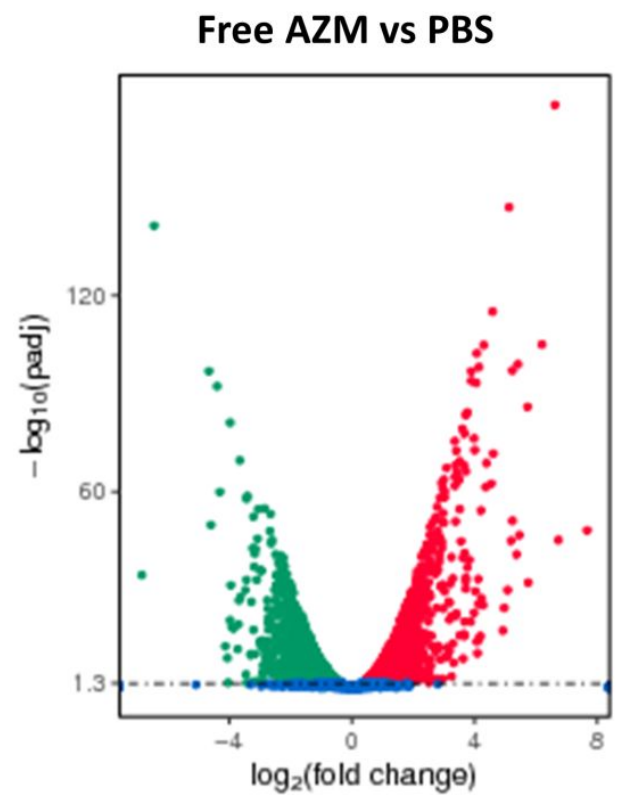

Differential Expressed Genes ( 3361 )

- up regialed: 1721

- down regulated: 1640

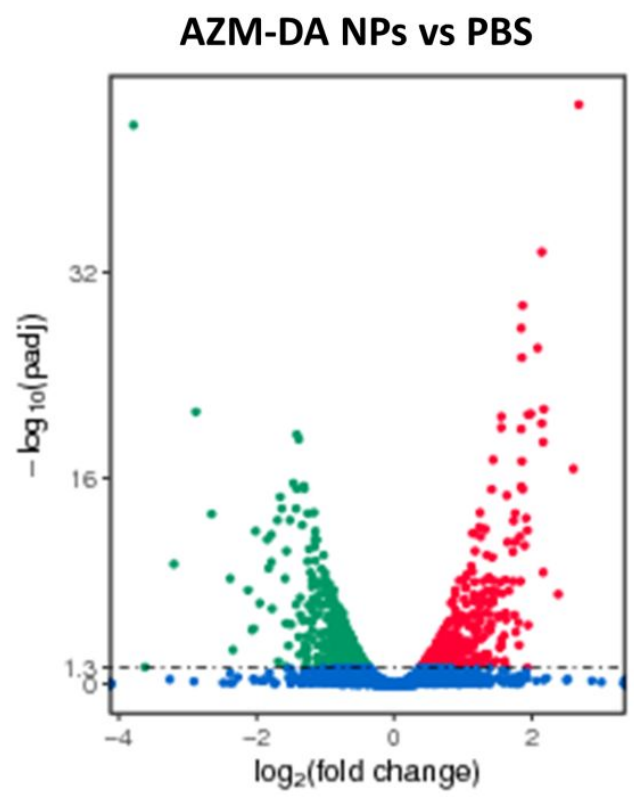

Differential Expressed Genes ( 869 )

- up regulated: 407

- down regulated: 462

Figure S14. Volcano plot of $P$. aeruginosa showing the amount of changed genes after treated with free AZM or AZM-DA NPs compared with untreated control. 


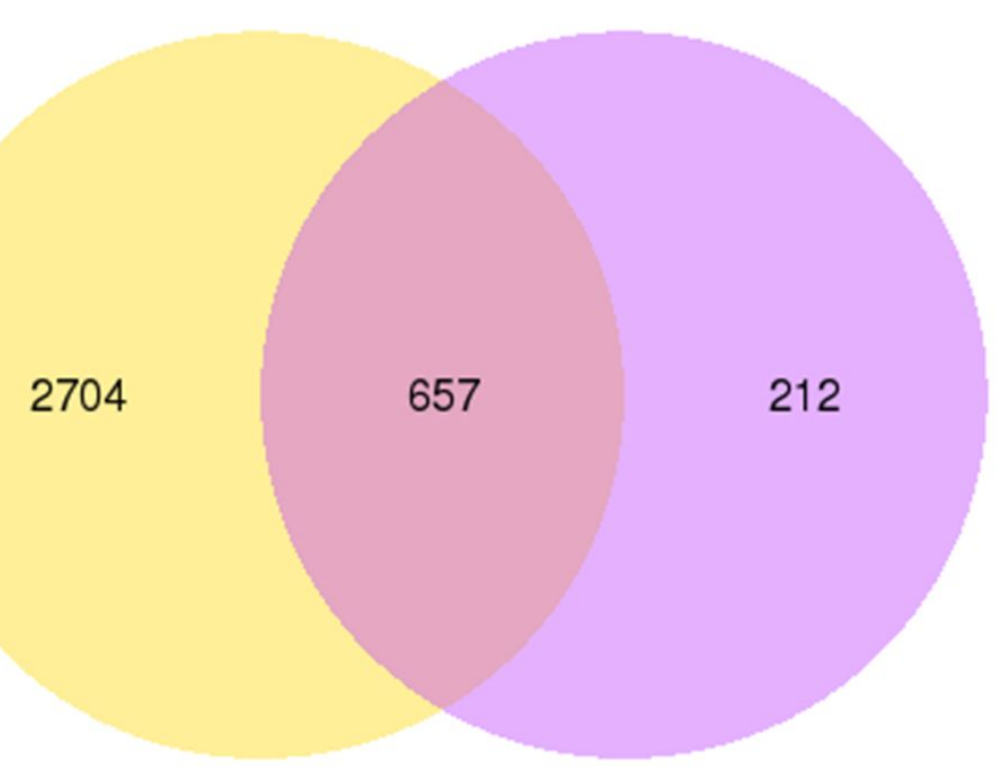

Figure 15.Venn diagram of $P$. aeruginosa showing the amount of changed genes after treated with free AZM or AZM-DA NPs compared with untreated control. 

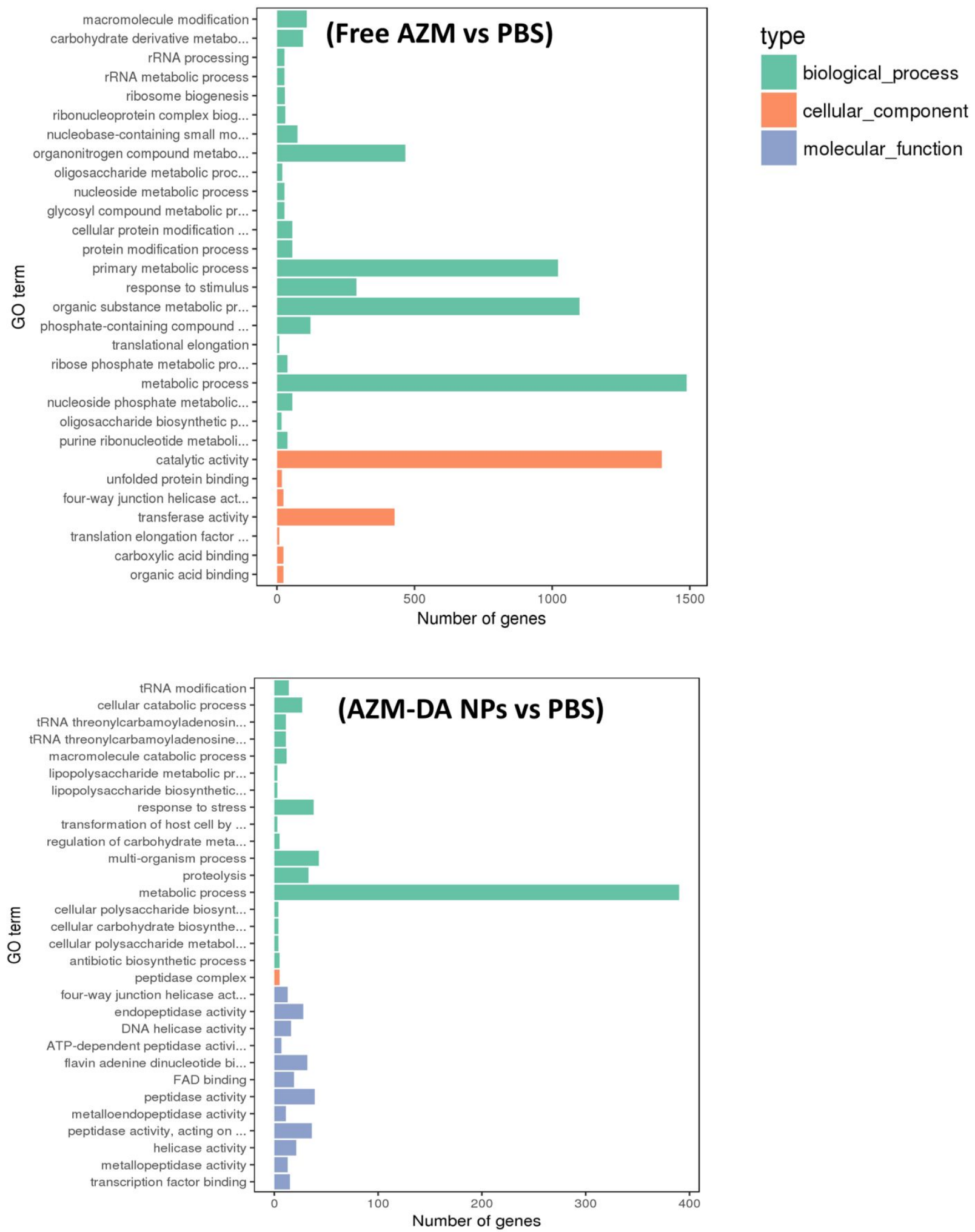
Figure S16. Enrichment Analysis Workflow of Gene Ontology (GO) processes for altered genes after treated with free AZM or AZM-DA NPs compared with untreated control.
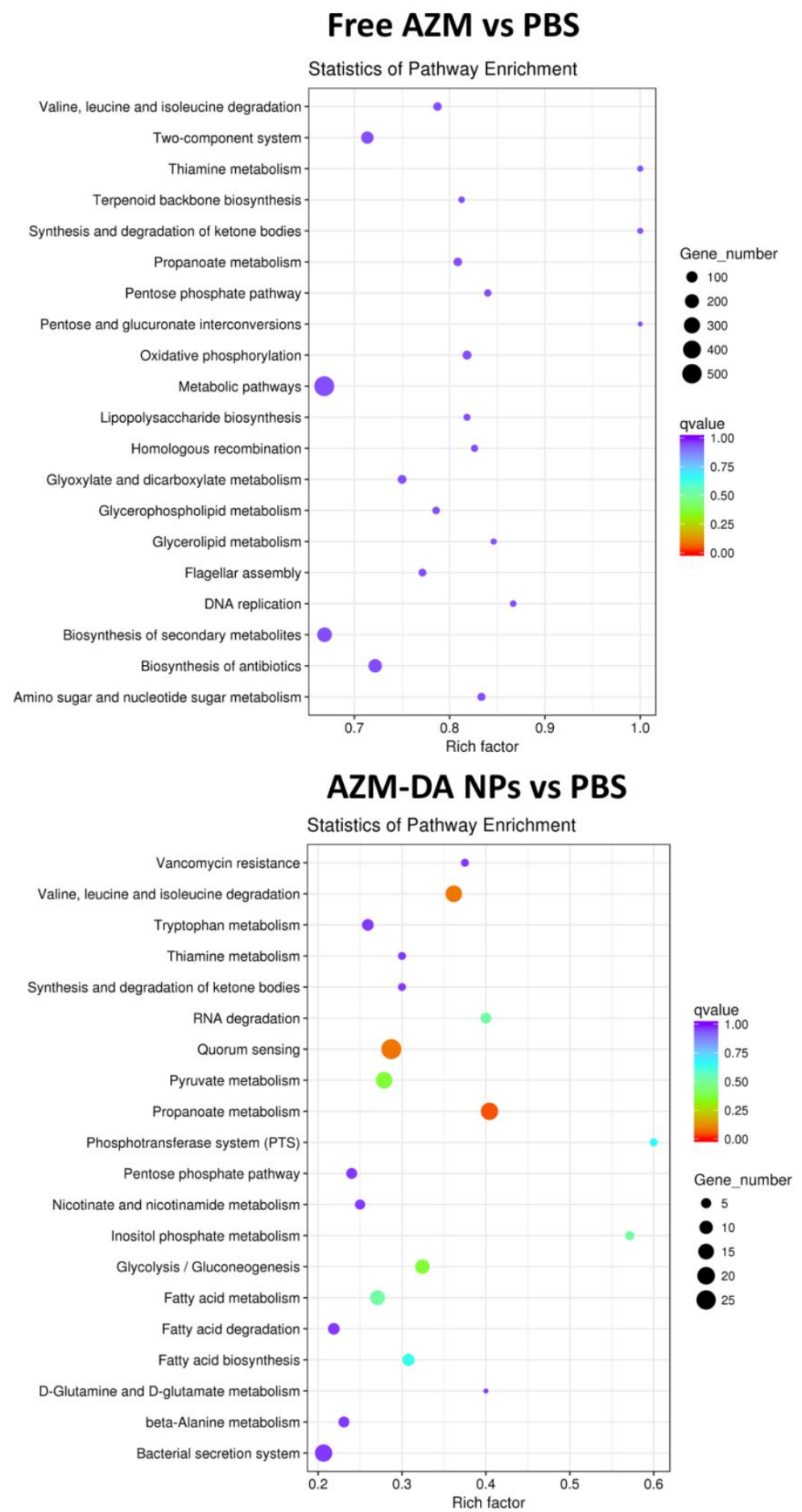
Figure S17. Enrichment Analysis Workflow of Kyoto Encyclopedia of Genes and Genomes (KEGG) pathways for altered genes after treated with free AZM or AZM-DA NPs compared with untreated control.

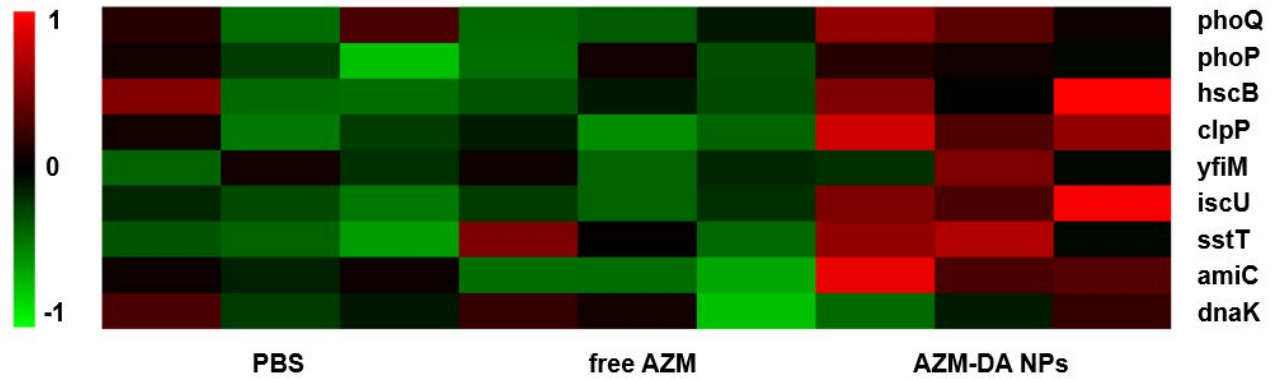

Figure S18. The heat cluster plot of membrane structure-related gene expression differences among $P$. aeruginosa treated with PBS, free AZM, and AZM-DA NPs obtained by transcriptome sequencing. 
(a)

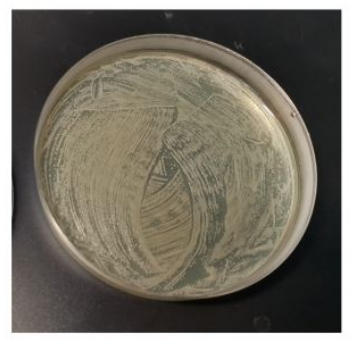

PBS

(b)

(b)
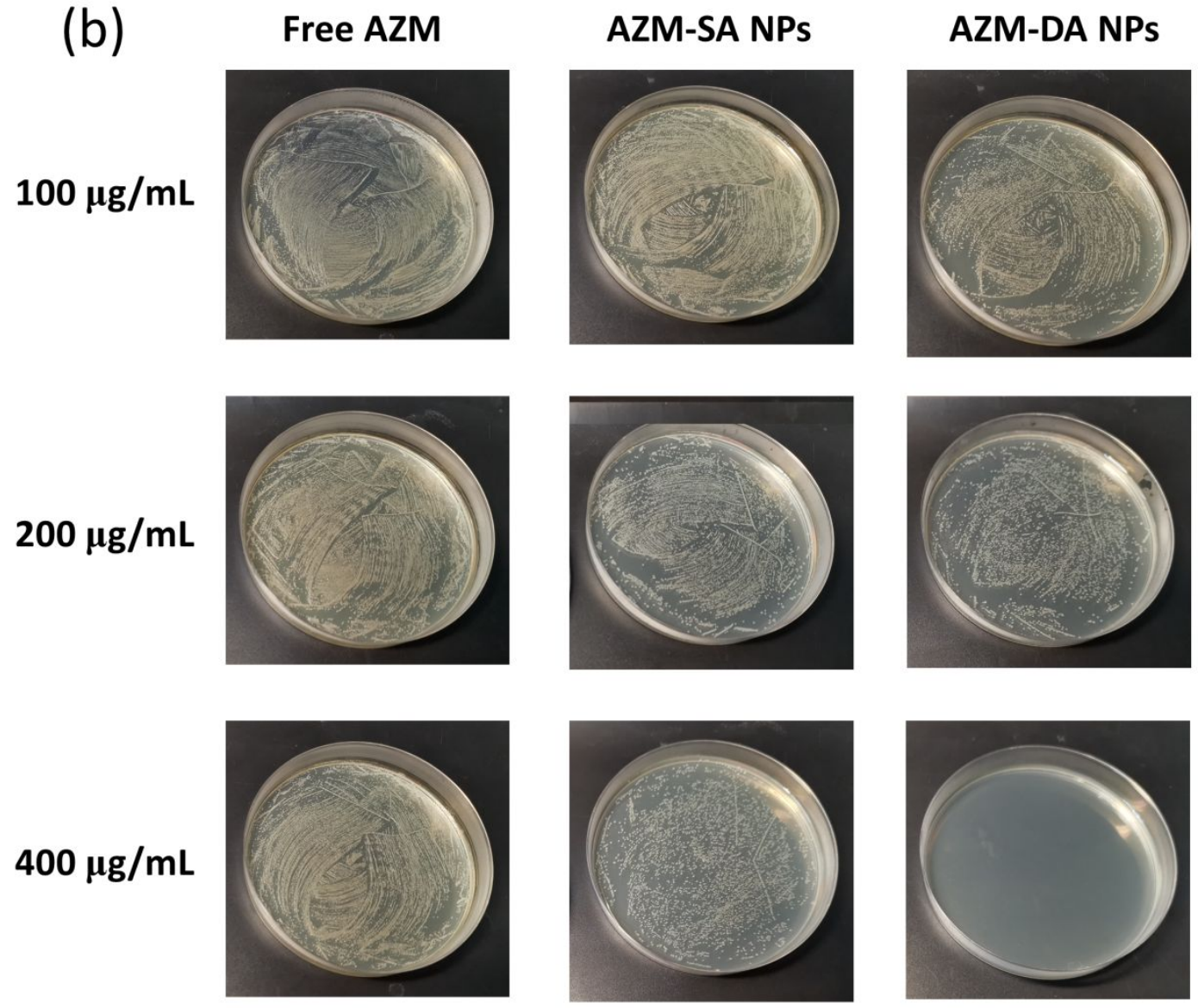

Figure S19. Biofilm killing results of $P$. aeruginosa treated with free AZM, AZM-SA NPs and AZM-DA NPs. 

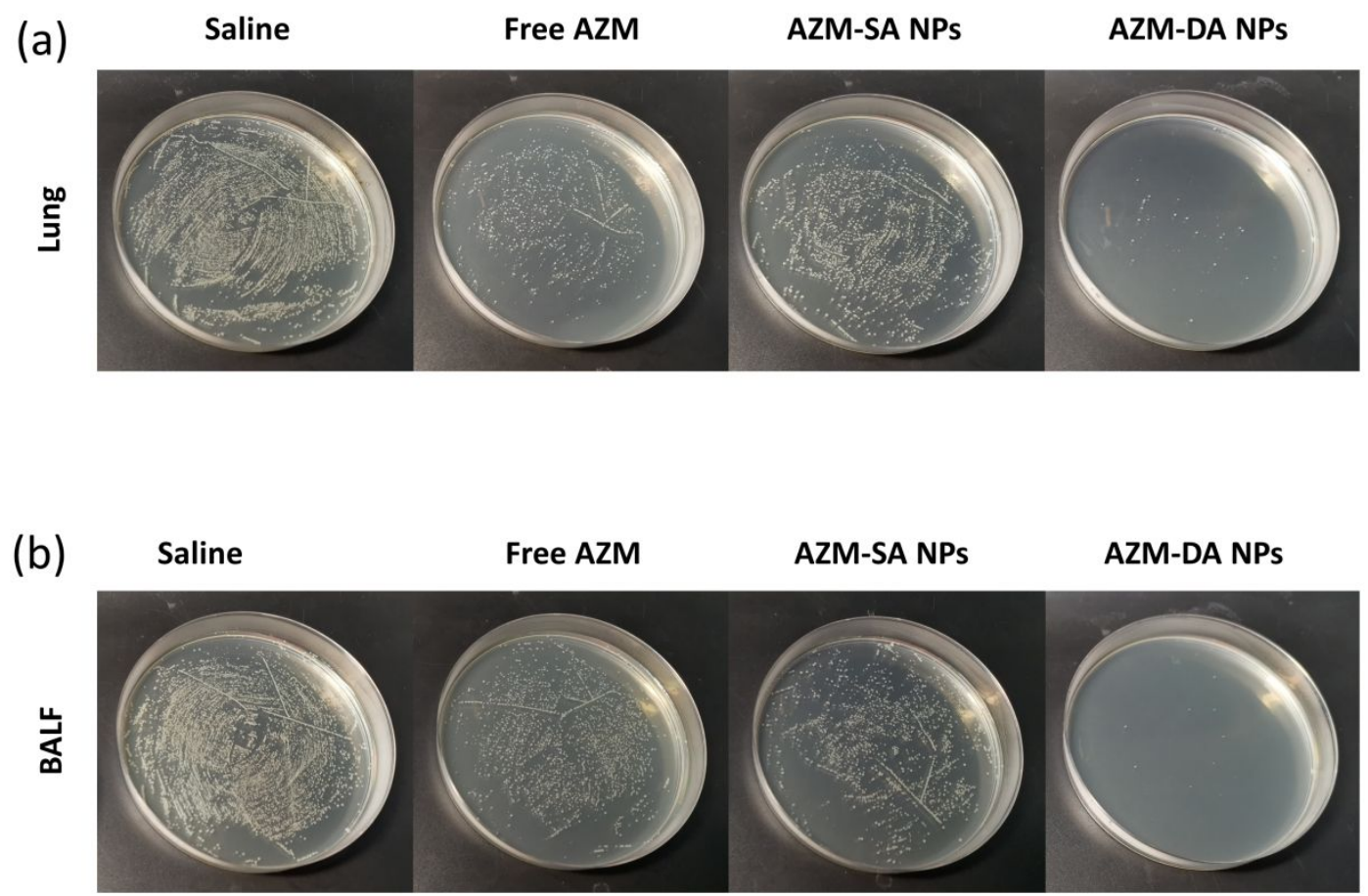

Figure S20. In vivo anti-biofilm results of mice injected with free AZM, AZM-SA NPs or AZM-DA NPs. Quantitative amount of bacteria in lung (a) or in BALF (b), respectively. 


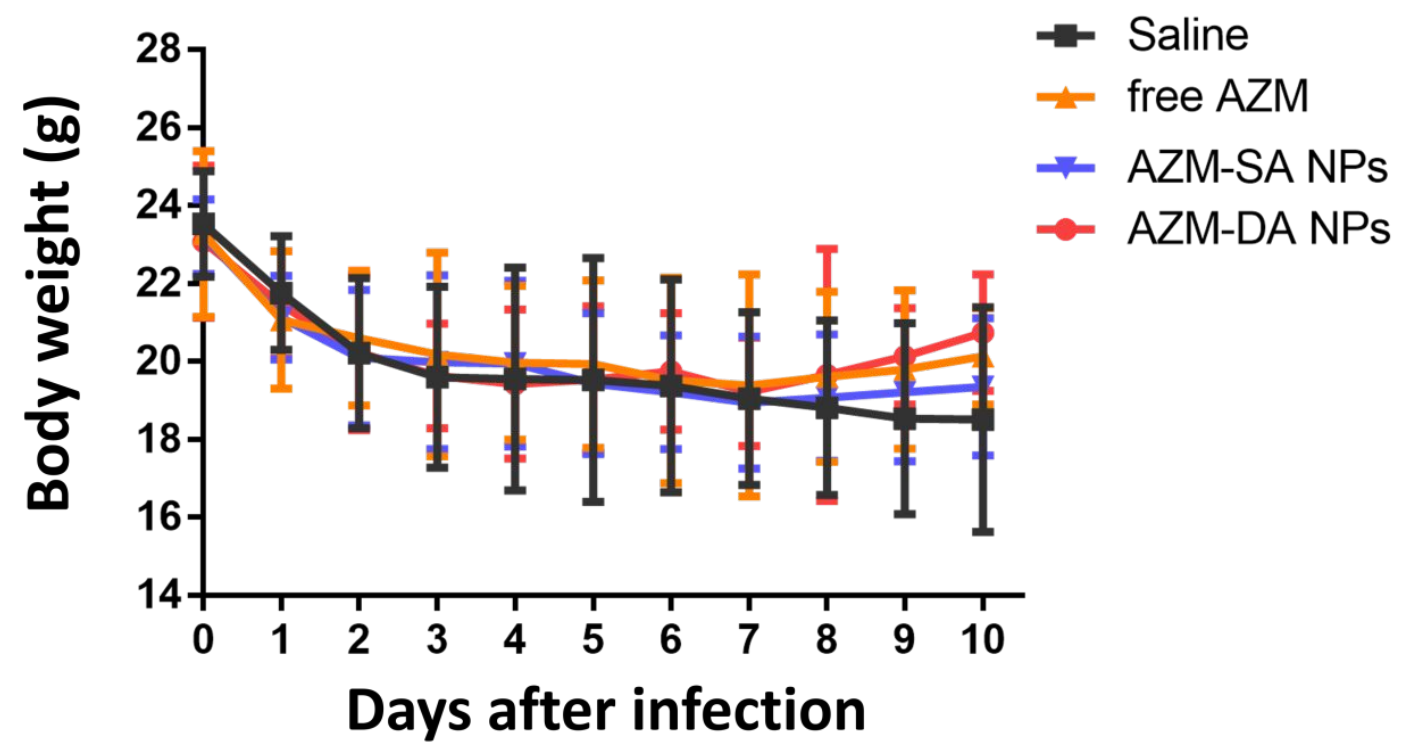

Figure S21. Body weight curves of C57BL/6 mice with chronic $P$. aeruginosa lung infection after different treatments. 